\title{
Near Net-Shape Fabrication of Superelastic NiTi Devices by Sputtering and Photoetching
}

\author{
Holger Rumpf*, Volker Wipperfürth, Christiane Zamponi and Eckhard Quandt \\ Center of Advanced European Studies and Research (caesar), Ludwig-Erhard-Allee 2, 53175 Bonn, Germany
}

NiTi-films were fabricated by DC magnetron sputtering from cast-melted disc targets. The obtained freestanding films revealed superelastic properties in tensile testing experiments. At $37^{\circ} \mathrm{C}$ superelastic properties were achieved showing a closed-loop hysteresis and a plateau of more than 5\% strain. Photolithography and wet etching technology were applied in order to fabricate net-shaped devices. Achievable structure sizes range in the order of the NiTi film thickness, i.e. typically between 5 and $15 \mu \mathrm{m}$. Tensile testing experiments reveal a remarkable strain tolerance of these devices which summed up to a superelastic strain of up to 5\%. It has been demonstrated that the deposition process can be transferred to the fabrication of NiTi tubes, which have high potential for application as vascular implants, e.g. stents.

(Received September 13, 2005; Accepted November 7, 2005; Published March 15, 2006)

Keywords: superelasticity, TiNi, sputtering, thin films, structuring, net-shaped structure

\section{Introduction}

Shape memory alloys based on binary NiTi can exhibit superelastic properties with strains larger than $8 \%$. Additionally, the material is known to reveal an excellent biocompatibility which allows its use for medical implants and devices. The most prominent example is the endovascular stent ${ }^{1-3)}$ which is formed out of tubes fabricated from bulk material by deep-hole drilling as well as subsequent wire drawing and structured by precision laser cutting technology. Aiming at a wall thickness smaller than $50 \mu \mathrm{m}$ which is supposed to be necessary for new stenting devices e.g. for neurovascular applications, bulk machining is envisioned to be replaced by thin film technology. Sputtering and sacrificial layer technology have been proven to be suitable methods for the fabrication of freestanding thin films revealing a film thickness between 5 and $50 \mu \mathrm{m}^{4-11)}$ and a superelastic strain up to $6.5 \%$ in tensile testing experiments. ${ }^{12)}$ Within this work, the realization of structured planar NiTi films is described and first net-shaped test structures were fabricated which seem to be potential candidates for e.g. stenting applications.

\section{Experimental}

NiTi disc targets of $100 \mathrm{~mm}$ in diameter were fabricated by cast-melting technology at the Mechanical Engineering Department of the University of Bochum. ${ }^{10,13)}$ Thin films of NiTi were deposited at $450^{\circ} \mathrm{C}$ in the crystalline state on silicon substrates using a vonArdenne CS730 sputtering cluster machine at a typical deposition rate of $13 \mu \mathrm{m} / \mathrm{h}$. The base vacuum was about $1 \times 10^{-5} \mathrm{~Pa}$. Due to the different angular sputtering distributions for nickel and titanium the film composition deviates from the composition of the target. In correspondence with analysis results published in our previous work, for the employed sputtering geometry a typical loss rate of 4-4.5 at\% Ti between cast-melted target and sputter deposited film was found. ${ }^{10)}$ Consequently, the target composition was chosen to be $\mathrm{Ti}-53.5$ at $\% \mathrm{Ni}-46.5$ at $\%$

*Corresponding author, E-mail: rumpf@caesar.de in order to obtain a composition of $\mathrm{Ti}-49$ at $\% \mathrm{Ni}-51$ at $\%$ in the films. Care has been taken to minimize oxygen contamination during the cast-melting process for target preparation as well as for the sputtering system. ${ }^{13)}$

Freestanding films of $50 \mathrm{~mm} \times 3 \mathrm{~mm} \times 15 \mu \mathrm{m}$ were obtained by mechanical release of the NiTi films from the silicon substrates whereas net-shaped structures as well as NiTi tubes were obtained by the use of a copper sacrificial layer $200 \mathrm{~nm}$ in thickness or a sacrificial copper tube, respectively. Post deposition temperature treatment was carried out within a high vacuum rapid thermal annealing system enabling heating ramps of $50 \mathrm{~K} / \mathrm{s}$ at a base pressure of $2 \times 10^{-6} \mathrm{~Pa}$ (unheated state).

Optical inspection of the specimen was carried out by means of a scanning electron microscope at $20 \mathrm{keV}$ (LEO Supra 55). The composition of the as-deposited films was determined by energy dispersive X-ray microanalysis (EDX: Oxford Instruments INCA 3.04). The film thickness was determined by a surface profiler (Tencor PL-10). Differential scanning calorimetry data were recorded between $-60^{\circ} \mathrm{C}$ and $150^{\circ} \mathrm{C}$ at a typical rate of $10 \mathrm{~K} / \mathrm{min}$ (Perkin-Elmer, DSC7). In order to start the DSC measurements from a defined austenitic state, samples were heated up to $150^{\circ} \mathrm{C}$ with a dwell time of $180 \mathrm{~s}$ before starting the measurement.

Tensile testing of freestanding films was performed in a universal tensile test machine (Messphysik UTM Beta EDC $100 \mathrm{~N}$ ) with the sample being located within a temperature chamber (Shimadzu TCL-N382). The gauge length of the samples was set at $25 \mathrm{~mm}$.

Structuring of sputtered NiTi films on a wafer basis was performed by wet etching technology in combination with UV-photolithography. For this purpose, 4 inch silicon wafers were covered with $\mathrm{NiTi}(12.5 \mu \mathrm{m})$ as well as a positive photoresist (AZ-1518) of $2.2 \mu \mathrm{m}$ in thickness by spincoating technology. UV-light exposure was performed at a Karl Suss mask aligner (MA6). The structuring step was performed by chemical wet etching using a standard silicon etch $(\mathrm{HF} /$ $\mathrm{HNO}_{3} / \mathrm{H}_{2} \mathrm{O}: 9 \% / 28 \% / 63 \%$ ). Due to the isotropic nature of the wet etching technology, undercutting effects occur which limit the achievable structure sizes to the thickness of the NiTi film. 


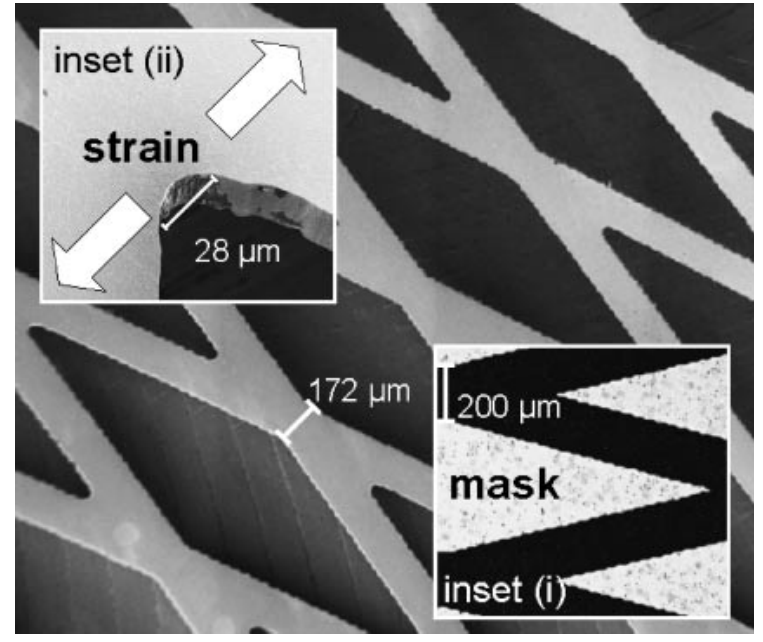

Fig. 1 The scanning electron micrograph of the freestanding NiTi net discloses a saw tooth shaped rim which has been transferred directly from the employed low-quality lithography mask illustrated in inset (i). Inset (ii) shows a magnified section of the near net-shaped structure during application of external tensile stress.

\section{Results and Discussion}

Secondary electron images of the NiTi film after removal from the substrate are depicted in Fig. 1 and show a film thickness of $12.5 \mu \mathrm{m}$. Due to the high deposition temperature of $450^{\circ} \mathrm{C}$, the sputtered films reveal a dense microstructure due to the high volume diffusion of the atoms deposited. ${ }^{12)}$ As test pattern for etching experiments, a diamond shaped mask design was chosen (see Fig. 1). For this first test a simple lithography mask (standard black and white transparency fabricated by offset printing technique) was used, giving a step resolution of only $10 \mu \mathrm{m}$. The corresponding limited resolution can be seen in Fig. 1 in comparison to the mask (insert).

A general drawback of this photoetching technique is the photo-etch-resist undercut due to the isotropic nature of the wet etching process. This results in a reduction of lateral feature size in the order of the film thickness, i.e. a reduction of the original mesh width of 200 to $172 \mu \mathrm{m}$ corresponding to a $14 \mu \mathrm{m}$ undercutting on each side of the mesh which is close to the film thickness of $12.5 \mu \mathrm{m}$. As illustrated in the inset (ii)

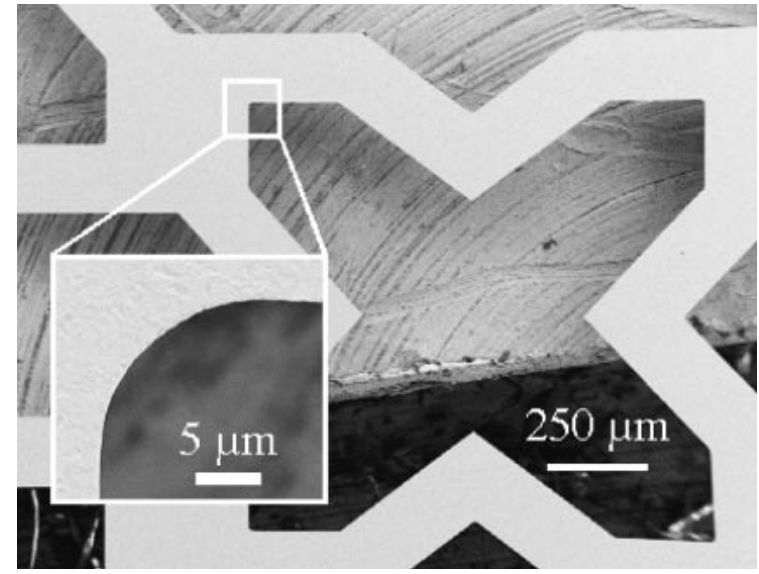

Fig. 2 Scanning electron micrograph of a NiTi net-shape structures $5 \mu \mathrm{m}$ in thickness when a standard chromium based photolithography mask is used.

of Fig. 1, this feature size reduction complies with a diameter of curvature of $28 \mu \mathrm{m}$ in the crossing points of the mesh. Due to the isotropic nature of the wet etching technology, the highest quality of rim structures would be achievable only when dry anisotropic etching technologies are applied.

When using a chromium covered quartz mask fabricated by electron beam writing, photolithography resolution can easily be improved to about $1 \mu \mathrm{m}$. Structuring of a $5 \mu \mathrm{m} \mathrm{NiTi}$ film was performed by means of such a mask in order to determine the achievable resolution of this method. Typical scanning electron micrographs of the freestanding films are depicted in Fig. 2. Inset (ii) shows that the saw tooth shaped rim obtained from the transparency based photomask is replaced by a very smooth high quality rim. SEM pictures were recorded to study the quality of the rim and are illustrated in Figs. 3(a) and (b). From the illustration, a typical rim roughness below $1 \mu \mathrm{m}$ can be extracted which is limited to incidentally occurring undercutting phenomena [Fig. 3(b)].

Differential scanning calorimetric analysis was carried out to investigate the martensitic transformation and to determine transformation temperature shifting as a result of post deposition annealing. A typical DSC curve is shown in Fig. 4, illustrating a martensitic transformation upon heating. The transformation peak temperature upon heating reaches a
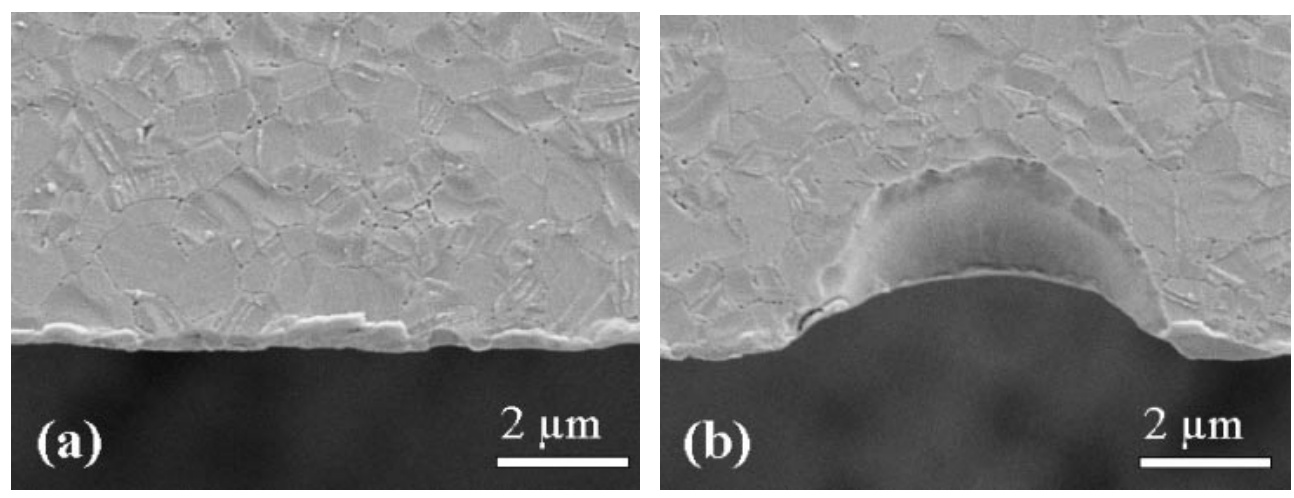

Fig. 3 Scanning electron micrographs disclose the typical rim quality of $5 \mu \mathrm{m}$ in thickness NiTi devices (a) as well as the influence of incidental undercutting due to the photoetching process (b). 


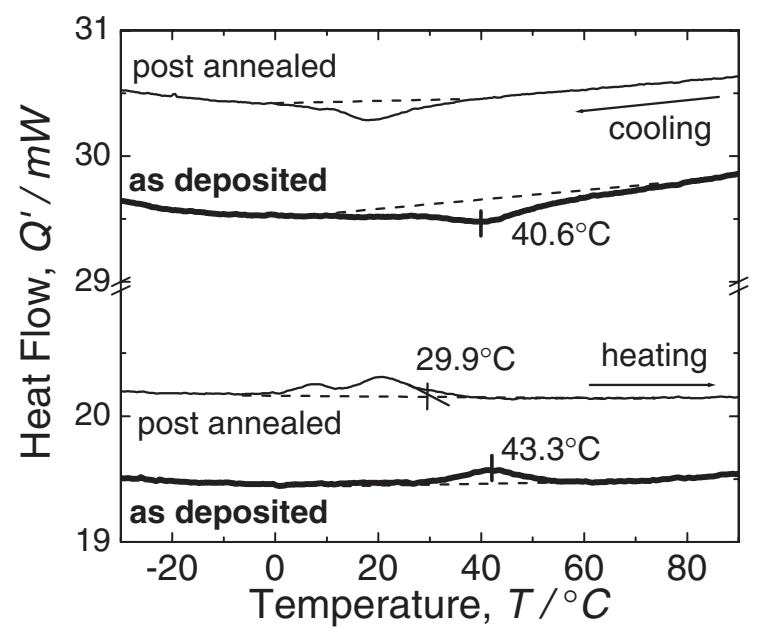

Fig. 4 DSC analysis of an as sputtered (thick line) and post annealed NiTi films (thin line) reveals a reduction of the austenite finish temperature to below $30^{\circ} \mathrm{C}$ when a rapid thermal annealing of $500^{\circ} \mathrm{C}$ for one hour is applied.

value of $43.3^{\circ} \mathrm{C}$ when no secondary post annealing is applied (thick line at the bottom), whereas upon cooling the transformation occurs at a peak temperature of $40.6^{\circ} \mathrm{C}$. The small difference between the peak temperatures upon heating and cooling also known as a narrow temperature hysteresis indicates the presence of an R-phase. Subsequent rapid thermal annealing at a temperature of $500^{\circ} \mathrm{C}$ for one hour led to a significant reduction of the transformation temperatures, which is already known from literature. ${ }^{14)}$ Tangent analysis of the heating part of the curve (thin line, secondary from the bottom) resulted into a reverse transformation finish temperature of $29.9^{\circ} \mathrm{C}$ permitting the occurrence of superelastic properties at blood heat $\left(37^{\circ} \mathrm{C}\right)$.

To demonstrate the superelastic effect of freestanding films, tensile testing was carried out at different temperatures. Figure 5(a) shows typical superelastic curves repeatedly exceeding a strain of 5\% at temperatures between 24 and $37^{\circ} \mathrm{C}$. More detailed studies were published in our previous work showing that no significant fatigue occurred after sixfold cycling a stress-strain hysteresis of $6.5 \%$ strain at $37^{\circ} \mathrm{C}^{12)}$ An ultimate tensile strength of $990 \mathrm{MPa}$ at a maximum strain of $7.9 \%$ was reached in this study which corresponds with earlier results $(\mathrm{UTM}=1180 \mathrm{MPa}$ at a maximum strain of $11.5 \%{ }^{12)}$ ).
The lithography-based structuring of the freestanding films did not diminish this remarkable mechanical stability. A typical tensile testing result for the diamond shaped structure is illustrated in Fig. 5(b) which gives proof for the resistance of the device to tensile stress. Since no numerical corrections for the net-shaped geometry have been accounted for [cf. inset of Fig. 5(b)], the absolute values for the stress as well as the slope of the "superelastic plateau" are misleading but a superelastic strain of $5 \%$ at $37^{\circ} \mathrm{C}$ can be extracted from the illustration [Fig. 5(b)].

\section{Outlook}

Future work aims at the transfer of the planar results of sputtering and structuring of NiTi on three dimensional objects. First experiments have been carried out which demonstrate the feasibility to realize cylindrical shaped objects of superelastic NiTi. ${ }^{11)}$ A typical result is shown in Fig. 6 which depicts the scanning electron micrograph of a sputtered NiTi tube of $400 \mu \mathrm{m}$ in diameter and $50 \mu \mathrm{m}$ in wall thickness.

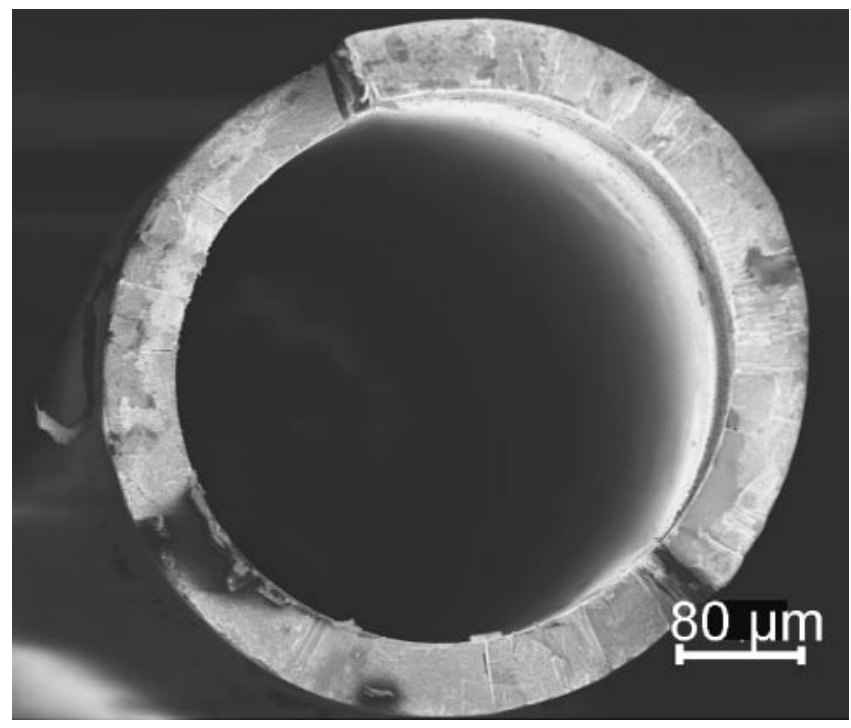

Fig. 6 NiTi sputtered cylinder of the dimensions $400 \mu \mathrm{m}$ (outer diameter) and $50 \mu \mathrm{m}$ in wall thickness as an example for the realization of threedimensional sputter objects.
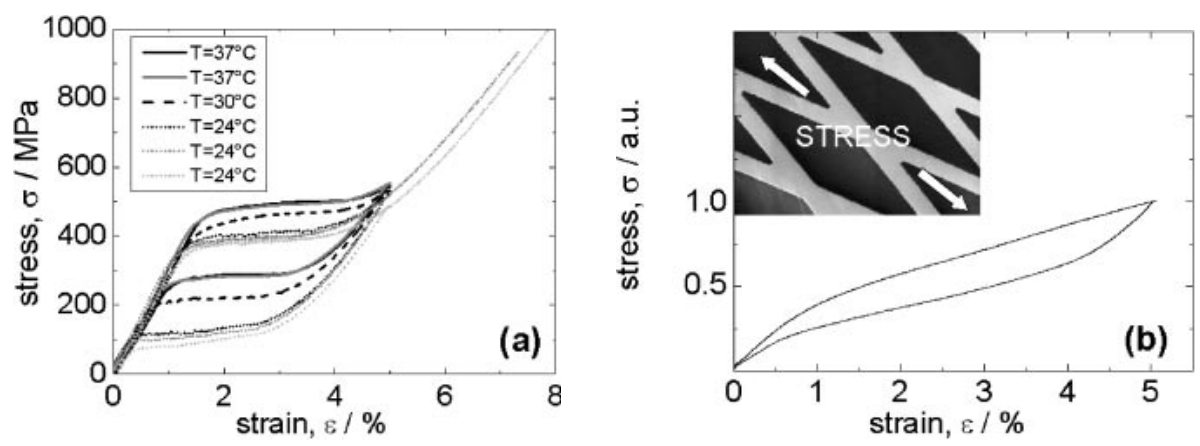

Fig. 5 Tensile testing experiments were carried out on freestanding films (a) as well as on photoetched structures (b) and reveal superelastic properties at and below $37^{\circ} \mathrm{C}$. 


\section{Acknowledgement}

Financial support of the German Federal Ministry of Education and Research (BMBF, contract 03N4031A) as well as the Deutsche Forschungsgemeinschaft through SFB 459 is gratefully acknowledged.

\section{REFERENCES}

1) T. W. Duerig, A. R. Pelton and D. Stöckel: Mater. Sci. Eng. A 273-275 (1999) 149-160.

2) D. Mantovani: Jom-Journal of the Minerals Metals \& Materials Society 52 (2000) 36-44.

3) K. Otsuka and X. Ren: Intermetallics 7 (1999) 511-528.

4) T. Saburi: Shape Memory Materials, ed. by K. Otsuka and C. M. Wayman (Cambridge University Press, United Kingdom, 1998) pp. 4996.
5) J. D. Busch, A. D. Johnson, C. H. Lee and D. A. Stevenson: J. Appl. Phys. 68 (1990) 6224-6228.

6) S. Miyazaki and A. Ishida: Mater. Sci. Eng. A 273-275 (1999) 106133.

7) V. Gupta, V. Martynov and A. D. Johnson: Actuator 2002 (2002) 355358.

8) M. Kohl, D. Dittmann, E. Quandt, B. Winzek, S. Miyazaki and D. M. Allen: Mater. Sci. Eng. A 275 (1999) 784-788.

9) B. Winzek and E. Quandt: Z. Metallkd. 90 (1999) 796-802.

10) H. Rumpf, B. Winzek, C. Zamponi, W. Siegert, K. Neuking and E. Quandt: Mater. Sci. Eng. A 378 (2004) 429-433.

11) H. Rumpf, C. Zamponi, C. Bourauel, D. Drescher and E. Quandt: Mater. Res. Soc. Symp. Proc. 855E (2004) W1.5.1-1.5.6.

12) H. Rumpf, T. Walther, C. Zamponi and E. Quandt: Mater. Sci. Eng. A 415 (2006) 304-308.

13) C. Zamponi, H. Rumpf, B. Wehner, J. Frenzel and E. Quandt: Materialwiss. Werkst. 35 (2004) 359-364.

14) A. Ishida, M. Sato, A. Takei, K. Nomura and S. Miyazaki: Metall. Mater. Trans. A 27 (1996) 3753-3759. 